\title{
The effect of the social values of ubuntu on team effectiveness
}

\author{
N. Poovan, M.K. du Toit and A.S. Engelbrecht* \\ Department of Industrial Psychology, University of Stellenbosch \\ Stellenbosch 7600, Republic of South Africa \\ ase@sun.ac.za
}

Received June 2006

\begin{abstract}
The study explores the management of South Africa's diverse workforce by analysing the impact of the social values of ubuntu on specific characteristics of team effectiveness. Semi-structured interviews were conducted with African Blacks who are members of successful work teams in a large South African company. The protocols were analysed by applying the methods of grounded theory. A conceptual model based on the canons of grounded theory was developed to explain how the social values of ubuntu could have a positive impact on team effectiveness. The study revealed that traditional African values, although in congruence with many universal ethical values, place more emphasis upon collectivism, collaboration, caring, dignity and respect. It is argued that these values should underlie a value-based leadership style to enhance team performance in modern organisations.
\end{abstract}

*To whom all correspondence should be addressed.

\section{Introduction}

Since the first all-race election in 1994, the South African labour market has increasingly incorporated African people as a result of affirmative action policies. Labour laws such as the Broad-Based Black Economic Empowerment Act passed in January 2004 brought about changes to the labour force for which few industries were adequately prepared. Today, South African organisations have a highly diverse workforce and are faced with issues concerning how this diversity can be managed more effectively. The co-existence and amalgamation of so many cultures within the society and each organisation indicate that different values and value systems exist. With employees subscribing to different values, the management of human resources and more specifically, teams becomes increasingly difficult (Johnson \& Johnson, 2003).

One might reason that the significant cultural differences could impact adversely on the efficiency, productivity and profitability of the organisation. This also calls for an understanding of the socio-cultural dynamics associated with a heterogeneous workforce (Yukl, 2002). In the wake of these challenges and due to the complexity of current business processes, South African organisations have come to rely on a team-based arrangement by which individuals from diverse backgrounds are required to work together.

Much of South Africa's management methods, practices, models and ideas are based on European and American management practices (April \& Ephraim, 2006). Constant reliance on European and American models might be too limited to manage and develop South Africa's diverse workforce, though. For this reason, April and Ephraim (2006), and Booysen (2001) emphasise the importance of harnessing uniquely South African managerial models from a collective cultural experience.

\begin{abstract}
Aim of study
The challenge for South African organisations is to find a leadership model that considers cultural differences, and optimises benefits from the diverse beliefs, values and principles that influence performance. When dealing with diversity management in the face of these challenges, it might be wise to consider an Afro-centric approach based on the value system of ubuntu. The primary aim of this study was to analyse the influence of the social values of ubuntu on team effectiveness. A secondary aim was to facilitate a better integration of the multi-cultural workforce into more effective and productive work units.
\end{abstract}

\section{The social values of ubuntu}

The Nguni word ubuntu, from the aphorism; 'Umuntu Ngumuntu Ngabantu - A person is a person because of or through others', can be described as the capacity in African culture to express compassion, reciprocity, dignity, humanity and mutuality in the interest of building and maintaining communities with justice and mutual caring (Bekker, 2006).

Based on the collective African way of life, Mbigi (1997) has extracted five key social values of ubuntu to create a conceptual framework, the collective finger's theory. The principle behind this theory can best be explained by the African proverb 'a thumb, although it is strong, cannot kill aphids on its own. It would require the collective cooperation of the other fingers' (Mbigi \& Maree, 1995: 110). The lesson in this proverb is two-fold. Firstly, the fingers can be seen as individual persons who act together in a 
collective manner in order to achieve a certain goal. Secondly, the fingers represent key values that are necessary to form and maintain a collective culture.

Mbigi (1997) argues that the five key values are survival, solidarity spirit, compassion, respect and dignity. These values have always been part and parcel of the African culture (Edwards, Makunga, Ngcobo \& Dhlomo, 2004). In the African context, these values are the 'assegais' (Zulu word for weapon or, more concretely, spear), which are used to defend brotherhood, manage society and guide interpersonal relations (Broodryk, 2002).

\section{Survival}

At the heart of ubuntu is survival. Survival can be described as the ability to live and exist in spite of difficulties. The African people learnt how to survive through 'brotherly' care and not individual self-reliance. As a result, Africans have developed a collective psyche and it is this psyche that allowed and still allows them to pool their resources, preserve, and creates the African communities. The period of struggle was a time to display personal responsibility, accountability, sacrifice, suffering and a spirit of service towards the survival of the community (Mbigi \& Maree, 1995). Through a collective and collaborative spirit, Africans have developed a shared will to survive.

In South Africa today, this kind of collective and unified tradition can still be observed in the poor African communities in the townships and squatter camps where people are obliged to share limited space, food, water and other resources.

\section{Solidarity spirit}

Very closely related to survival is a spirit of solidarity that developed through the combined efforts of individuals in the service of their community. Mbigi (1997) confirms that Africans, from early childhood, are socialised to understand that difficult goals and tasks can only be accomplished collectively.

The idea of the 'self' becomes entrenched in the community and the individual identity of an African almost does not exist. For Mkize (as cited in Nussbaum, 2003: 3) 'the African view of personhood denies a person can be described solely in terms of the physical and psychological properties. It is with reference to the community that a person is defined'. Personal interests become less important than community needs. Feelings of pride and responsibility are contextualised within the community.

The bonds of solidarity, which to an African consist of interpersonal, biological and non-biological bonds, are created and maintained through spiritual values. The solidarity spirit permeates every aspect of an African's life and is collectively expressed through singing, effort at work, initiation and war rites, worship, traditional dancing, hymns, story telling, body painting, celebrations, hunting, rituals and family life (Nussbaum, 2003).

\section{Compassion}

Compassion is another key social value of ubuntu (Nussbaum, 2003). Compassion is a human quality of understanding the dilemmas of others and wanting to help them. In the African milieu, however, compassion is the reaching out to others and practising humanism so that relationships and friendships can be formed (Broodryk, 2002). The underlying belief amongst Africans is that all human beings are interconnected and share a common and communal responsibility for each other.

From an early age, Africans learn that they are interconnected with each other and that sharing and giving is the only way one can receive. They believe that they belong to a larger community and that acts of compassion create and maintain this interconnectedness amongst human beings. This is why most Africans are willing to help members within and out of their community. 'Ukwenana' is an act practised by most Africans and it entails giving unselfishly without expecting anything in return (Nussbaum, 2003).

When one is socialised within a culture that encourages helping others, it becomes part of one's psychological makeup and it is difficult to unlearn such a quality. For an African, these compassionate acts show a kind love, which is an important part of the communal lifestyle (Bekker, 2006).

It is when these values seem to be disregarded during incidences of internal political strife and violence that outside observers come to doubt the validity of ubuntu as a guiding force in modern society (Enslin \& Horsthemke, 2004). The condition of anomie (Durkheim in Babbie \& Mouton, 2001) that has followed on social disintegration as a consequence of political suppression, severe poverty and traumatic urbanisation, has not been ignored, but has fallen outside the parameters of this particular study.

\section{Respect and dignity}

In general, respect refers to an 'objective, unbiased consideration and regard for rights, values, beliefs and property' (Yukl, 2002). Respect and dignity are considered important values in most societies and cultures. In the African culture, it is even considered as one of its building blocks (Bekker, 2006).

'Ukuhlonipha', meaning respect in the African language, is one of the most central values of the ubuntu world view as it stipulates the social position of an African in society, as well as brings forth and highlights a whole set of authoritarian and hierarchical relationships.

Closely related to respect is dignity (Bekker, 2006). The Oxford dictionary (1988) delineates dignity to be a quality that earns or deserves respect. From childhood, Africans learn that behaviour towards those in authority, such as the king, the elders and other members of the community, should always be respectful and these members of society become dignified through respect. 
Respect and dignity, together with survival, solidarity spirit and compassion, constitute the African value system of ubuntu. As more and more Africans are empowered to progress within, work in, and even manage South African organisations, this value system has to be taken into consideration for managing diverse teams in South Africa effectively (Mangaliso, 2001).

\section{The effect of the social values of ubuntu on team effectiveness}

When examining the possible effect of ubuntu on team effectiveness, it can be postulated that relationships exist between certain values of ubuntu and certain characteristics of effective teams. In this section, the influence of the values of ubuntu on specific characteristics of effective teams will be explored. These characteristics include knowledge, skills and abilities; cohesion; shared vision and mutual trust (Buskens \& Raub, 2002; Holton, 2001; Johnson \& Johnson, 2003; Robbins \& Finley, 2000; Yukl, 2002).

\section{The value of survival and the team characteristic of knowledge, skills and abilities (KSAs)}

Team members may be called upon to utilise their unique knowledge, skills and abilities (KSAs) in order to lead the team forward and to ensure the success of the team. The very nature of a successful team requires its members to jointly overcome a variety of problems and to fulfil different roles. Therefore, KSAs should be complementary in nature (Johnson \& Johnson, 2003).

Daily challenges can hinder the productivity and performance of a team and it therefore becomes important that team members realise that lack of tolerance for cultural differences in the team can result in low performance (Yukl, 2002). Team members need to realise that the survival of the team (maintaining high levels of productivity and effectiveness) can be achieved when all members pool their resources, such as their knowledge, skills and abilities (KSAs). According to Mangaliso (2001), the chances of a team surviving are higher when recognition is based on similarities, in other words on shared values, rather than on differences.

According to Mbigi (1997), the greatest threat to the survival of teams is conflict between team members. If team members put aside their cultural and other differences and focus their attention on the need for survival (to be effective and productive), they would realise that the team's effectiveness is achieved through reliance on each other. This reliance on each other implies that personal goals are sacrificed for the goals of the team. As a result of their reliance on each other, a culture of collaboration and collectiveness within the team will be created. Through the value of ubuntu, the leader will be able to bring together the different kinds of knowledge, skills and abilities (KSAs) of people in continued team efforts (Van der Colff, 2003).

\section{The value of solidarity spirit and the team characteristic of cohesion}

Yukl (2002: 327) defines cohesion as 'the amount of mutual affection among members and attraction to the group'. It has often been argued that a high degree of cohesiveness culminates from certain characteristics that team members possess, such as high degrees of agreeableness, motivation, loyalty and commitment to the team (Wheelan, 1999).

The value of solidarity spirit can increase cohesion among team members. By instilling the value of 'solidarity spirit it is possible to build co-operation and competitive strategies by allowing teamwork to permeate the whole organisation' (Mbigi \& Maree, 1995: 9). The ubuntu value has the ability to create a bond between team members because it places emphasis on the achievement of tasks collectively rather than individually.

According to Mbigi and Maree (1995: 5), the 'solidarity tendency could be the basis of building a culture of empowerment and teamwork in the workplace'. Team members can be encouraged to change their thinking from ' $\mathrm{I}$ can' to 'We can'. It implies that team members would have to sacrifice their own personal goals for the goals of the team like so many Africans have sacrificed their personal goals for their community.

Teams that develop a spirit of solidarity tend to have a heightened morale and increased community feeling which can become the basis for an effective team. In addition, teams that embrace the solidarity spirit are more cohesive. According to Thompson (2000: 79), cohesive team members display the following behaviours: (a) They sit together, (b) Focus more attention on one another, (c) Show signs of mutual affection, and (d) Display coordinated patterns of behaviour. Through these behaviours, team members forget about their personal goals and the goals of the team become important. Team members lose their 'I' mentality and have it replaced by the 'We' mentality.

Various studies have indicated 'some level of cohesion is a necessary requirement for the continuance of any team.' (Willer, Borch \& Willer, 2002: 67). Willer et al. (2002) argue that the higher the level of solidarity in a team, the higher the chances that team members will remain in the team. Therefore, solidarity is a necessary condition of team cohesion and commitment.

\section{The value of compassion and the team characteristic of shared vision}

According to Van der Colff (2003) and Senge (1990), a vision that is shared instils a sense of commitment, belief and teamwork amongst team members because it mirrors team member's personal goals. A shared vision is an initiating factor, which increases the ability of team members to perform at optimal levels.

By instilling feelings of compassion in team members, this value can help to create a shared vision. According to Senge (1990), a vision emanates from team members' personal visions, which are derived from the power of an individual's 
deep caring for the vision. This deep caring can be equated to the social value of compassion. Therefore it is through compassion that team members can develop a shared vision.

Mangaliso (2001) asserts that helpfulness towards others creates a climate of collegiality that is based on sharing and caring. Africans find it easy to be compassionate to other human beings because of their personal understanding that all humans are interconnected. Similarly, members of a team can also create a shared vision through personal understanding and caring for each other. This personal understanding and caring will enable the team members to see themselves as belonging to the team, as a 'bigger picture', and they will be more willing and committed to help each other.

With a value such as compassion, the leader and team members can create a culture that promotes a vision that is shared. All members will be directed towards a shared vision because they experience belongingness in the same social network.

\section{The values of respect and dignity and the team characteristic of mutual trust}

Without trust, the efficiency of human interactions would not exist (Buskens \& Raub, 2002). Robbins (1999: 336) defines trust as a 'positive expectation that another will not through words, actions or decisions - act opportunistically to one's detriment'. Mutual trust in a team is created through frequent and meaningful interaction, whereby team members feel comfortable and open in sharing their individual insights and concerns (Holton, 2001). No team can reach its highest potential without high formalisation of mutual trust. According to McFarlin, Coster and MogalePretorius (1999), it is mutual trust that acts to eliminate uncertainty and ambiguity amongst team members.

Team members who show mutual trust for each other create a positive climate, which in turn creates an effective team. Without trust amongst team members, the chances of the team being successful and effective are minimal because each team member's activity is undermined (Robbins \& Finley, 2000).

Respect and dignity are values that are not solely African (Bekker, 2006). Therefore it will be easier for all team members to understand and accept the implementation of such values. The ubuntu values of respect and dignity are cardinal social values in the collective fingers theory, since it is only through respecting others and according them dignity that one gains the trust of others. Mbigi and Maree (1995: 6) argue that interpersonal relationships should be managed on the basis of unconditional acceptance and positive regard. Unconditional respect is the basis of effective performance and relationships essential for high performance'.

It therefore is clear that teams often fail to meet goals because team members do not treat one another with respect and dignity. In addition, high levels of respect and dignity would essentially lead to high levels of mutual trust, which will eventually result in effective team characteristics and performance.

From the discussion so far, it seems that the social values of ubuntu can have a positive impact on certain team characteristics and lead to team effectiveness. The question now arises: how can these values be instilled in the team in order to enhance the management of diverse teams and improve the team's effectiveness?

\section{Value-based leadership}

One possible approach as to how values in general and the ubuntu social values in particular can be instilled in a team is by applying value-based leadership. Value-based leadership facilitates the creation of a climate that nurtures positive values in a team. Value-based leadership is a values-driven, change-orientated and a developmental style of leadership. The purpose of this style of leadership is to help team members to change and grow in order to become proactive contributors to team effectiveness (Fairholm, 1991; Overbeek, 2001).

Value-based leadership is distinguished from the rigid, structural traditional forms of leadership through its humanitarian foundation and outcomes-based nature, which promotes organisational functioning to the advantage of those involved (Kuczmarski \& Kuczmarski, 1995). Transformational leadership, servant leadership and authentic leadership are closely related to value-based leadership since these leadership behaviours are all primarily driven by ethical values (Avolio \& Gardner, 2005; Engelbrecht, Van Aswegen \& Theron, 2005).

Value-based leaders have the ability to create a values-laden culture within the team. This culture entails (1) equal participation in decision making, (2) support of risk taking, (3) confronting change, (4) developing a sense of community amongst team members, (5) conveying passion and strong emotional conviction and (6) instilling values which generate a sense of belonging and belief in the goals amongst team members (Kuczmarski \& Kuczmarski, 1995).

Creating a value system that all team members agree upon could be a difficult task in South African organisations, because of the existence of diverse teams. Each team member may offer different cultural contributions, which may lead to contradictions. For example, certain values may differ along lines of race, gender, age, upbringing and education (Schlechter \& Maritz, 2001).

In the wake of these issues, it would be wise for South African leaders to develop a values-based style of leading which incorporates the social values of ubuntu. Particularly, Afro-centric leadership is founded on an inclusive ubuntu based value system, where the collectivist notion of the interdependence of people is recognised in the workplace (Thomas \& Schonken, 1998). The concept of Afrocentricity promotes a moral and spiritual transformation in African culture to reintroduce principles of communalism, participation and connectedness to African people, thereby producing a uniquely African leadership style. It seeks to modify African traditions to meet the demands of modern 
society and focuses on the introduction of characteristically African ethics and practices into management (Asante, 1991). However, Afro-centric leadership incorporates elements of ethnocentrism, which may have an adverse effect on the management of diversity (Yukl, 2002). Therefore, a value-based leadership style that is sensitive to African value systems would be more applicable for the management of diversity in organisations in South Africa.

Ubuntu values are not exclusively African; they can also be seen as universal humanistic values (Bekker, 2006; Engelbrecht, 2002). For Van der Colff (2003), these values are general leadership values that should be practised by excellent leaders. Therefore, the social values of ubuntu can be incorporated into the corporate world to create not only a value-centred and inclusive culture, but also to develop a network of values that is appropriate for the diverse workforce in South Africa.

\section{Theoretical model}

The model shown in Figure 1 was conceptualised on the basis of the information derived from the literature overview (Broodryk, 2002; Edwards, et al., 2004; Johnson \& Johnson, 2003; Kuczmarski \& Kuczmarski, 1995; Mangaliso, 2001; Mbigi, 1997; Nussbaum, 2003; Robbins \& Finley, 2000; Thomas \& Schonken, 1998; Thompson, 2000; Van der Colff, 2003; Willer, et al., 2002). It is a general model, depicting how the values of ubuntu can have a positive effect on the four team characteristics that are significant for team effectiveness. The purpose of the model was to illustrate how the study fits in with current leadership practices, ideas, methods and models. Therefore the model also depicts the role of a values-based leadership approach for the implementation of the value system of ubuntu in order to enhance team effectiveness.

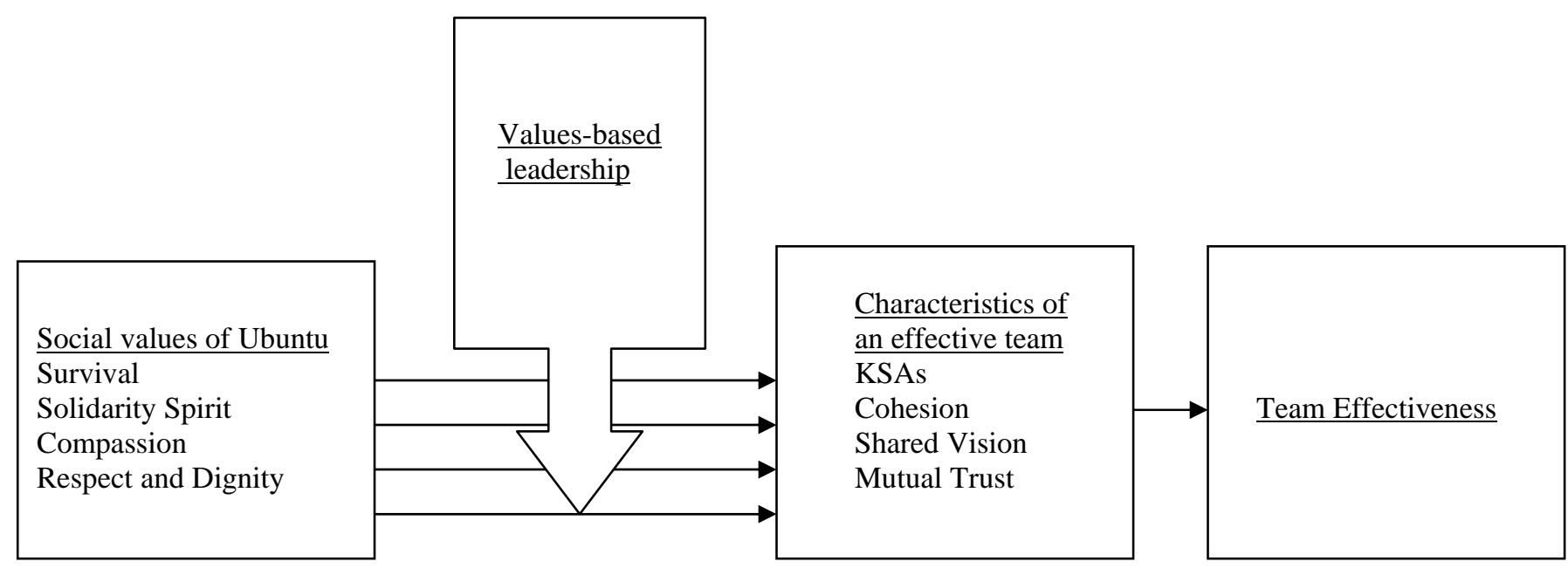

Figure 1: Theoretical model depicting the relationship between the social values of Ubuntu, values-based leadership, effective team characteristics and team effectiveness.

\section{Research methodology}

No empirical study could be found on ubuntu as an Afrocentric value system to be implemented in the management of a team. In order to gain preliminary understanding of the social values of ubuntu, a qualitative research methodology based on the grounded theory was used.

Grounded theory provides a systematic framework for inductively generating theory from data instead of the other way around (Glaser \& Strauss, 1967: 2). The intention underlining grounded theory 'is to generate or discover a theory, an abstract analytical schema of a phenomenon that relates to a particular situation. This situation is one in which individuals interact, take actions, or engage in a process in response to a phenomenon' (Creswell, 1998: 56). The idea is that the raw data should speak for itself; to reveal the innermost experiences of the individual, unblemished by statistical or hypothetical manipulation.

\section{The research participants}

Sample sizes in qualitative research traditionally are small (Creswell, 1998). In this study, 14 participants were interviewed. The interviewees were chosen on the basis of their relevance to the research question rather than their representativeness in terms of other criteria. This particular sample consisted of employees in the sales and warehousing departments of a company in the liquor industry in the Western Cape of South Africa.

As the study focussed on ubuntu and teams, the participants in this study had to:

- $\quad$ Belong to a team that displayed results of continued effectiveness. The team manager(s) singled out the teams who showed continued effectiveness.

- Volunteer their participation.

- $\quad$ Be of African origin. Grounded theory prescribes a homogeneous sample when conducting research. In this study, these were individuals who had an intimate experience of the phenomenon of ubuntu and were able to articulate their experiences very clearly. In this way the researcher was able to gain firsthand experience and understanding of how African people integrate ubuntu in the construction of their perceptual worlds. 


\section{Data collection}

The data was generated through tape-recorded in-depth interviews, which focussed mainly on what constitutes a good team, what the social values of ubuntu are, what these values mean to African people and whether ubuntu is practised in their respective teams. This allowed for the full exploration of the participants' beliefs and interests because of the open-ended nature of the questions, participants could provide a more spontaneous account of their social beliefs.

\section{Analysis of data}

Following the interviews, the data was manually transcribed verbatim. In this study, the categories of information were initially formed and after this had been completed, the data were reassembled by systematically relating the categories to the theory. The data were analysed by using the fundamental data analytical tools outlined by grounded theory, comprising the three coding methods and theoretical memo-ing, theoretical sampling and the identification of a core category (Glaser \& Strauss, 1967).

Each sentence of the transcribed interviews was read and then re-read in a line-by-line analysis. This is known as open coding, whereby the data are examined word-by-word and line-by-line and codes are freely generated, often reflecting the words of the respondents themselves. Ordering the most important words or phrases into categories and subcategories continues this method of coding. The data were examined and then re-examined until the point of saturation was reached.

In axial coding, categories were related to their subcategories. This allowed for the exploration of ways in which the categories were related to each other. It was through this type of coding that the interconnectedness between categories could be established. In this step, the single categories resulting from the open coding were integrated to form a unified data set. Selective coding is the process of integrating and refining theory so that hypothetical relationships between the various categories can be established. This finally completed the grounding of the theory on the social values of ubuntu and their impact on team effectiveness.

\section{Validity}

In this study, the researcher continually ensured that the data collection methods were valid by:

(a) Checking for bias, neglect or lack of precision in the research methodology. Since the researcher had some theoretical knowledge of the concept of ubuntu, the researcher when coding data, could not approach the raw data in a fully objective way, as prescribed by grounded theory. The researcher was aware of this lack of objectivity and ensured that the terminology of existing categories was carefully employed.

(b) Ensuring that the procedures were questioned critically. (c) Discussing the knowledge or verifying the data with the research participants. Multiple visits to the field were made after the process of transcribing and open coding in order to make sure that the collected data represented what the participants wanted to express. The participants were given the opportunity to rank the researcher's understanding in order to verify the data analysis.

\section{Reliability}

Since interviews were the primary source of data, the reliability of interviews became a concern for the researcher. In order to overcome this concern the researcher tried to ensure that each participant in the study understood the questions in the same way by asking the questions in the same way. In addition, the participants were asked only about what they knew and what was relevant to them concerning ubuntu and their team functioning. This concentrated focus, it was assumed, would foster responses to be coded without the possibility of uncertainty.

\section{Ethical considerations}

Researchers have an obligation and responsibility to always conduct and document their research ethically. In order to maintain the credibility of this study, the prescribed guidelines provided by the Health Professions Council of South Africa were followed throughout the research. Prior to the beginning of the interview process, the researcher examined the prescribed code of ethical behaviour extensively. As a result, the nature and purpose of the research was verbally explained to all the participants of the study before the commencement of the first interview. Participation was voluntary and confidentiality was assured.

\section{Discussion of results}

In this section, a detailed interpretation of the main findings that emerged from the interviews will be discussed. Some of the identified sub-categories in the study correspond with terminology already identified in the literature overview.

The central category that emerged from the data is collectivism; this is the main and overarching theoretical concept that emanated from the research. This category fitted the grounded theory's criteria for being classified as a central category. This central category and its various subcategories are depicted in Figure 2. 


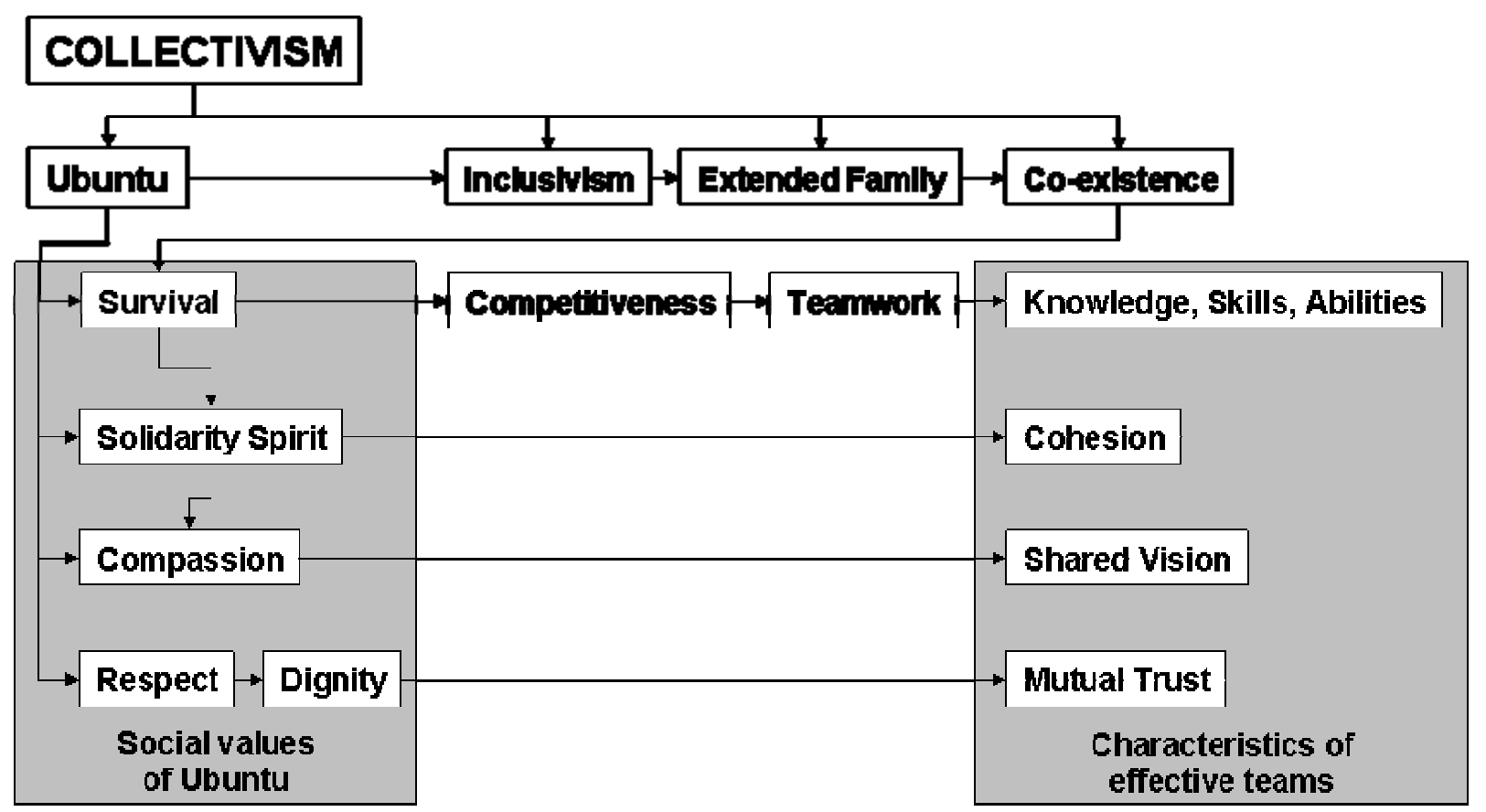

Figure 2: Central category and subcategories that emerged from the study

African culture in South Africa can be characterised as collectivistic (Nussbaum, 2003). The Collectivistic nature of the African culture can be seen in the meaning of the underlying value system of ubuntu. Ubuntu means humanity, or, in a simpler explanation, that the existence of an individual impacts on others around him or her. As such, it is not about the individual, but rather about the collective. Through a collective mind-set, equality amongst members of the community can develop because there is a sense of being part of a bigger whole, a bigger community. One participant expressed how equality in the African community is encouraged, as:

Wiseman: 'this person is a human being no matter what colour, pink or white or brown'

African communities place more emphasis on belonging to the collective than other communities. This once again shows the inclusivistic and all-encompassing nature of African communities. The following quote illustrates this collectivistic and inclusivistic nature of ubuntu:

Vusi: 'It is about the collective, it's all about inclusiveness, it kind of eliminates the I. It's more about the we, the collective as opposed to I'.

As soon as an individual is included into the community, that person begins to appreciate the idea of having an extended family. This extended family is not based on biological bonds but rather on bonds of solidarity. Seeing oneself as a part of an extended family provides one with an identity. This identity makes one realise that all people within the collective share the same commonality in life. What can emerge out of the idea of being part of and having an extended family is co-existence. Through co-existence, individuals become interdependent on each other for their survival. One participant explained his understanding of (1) belonging to an extended family, and (2) survival:

Sibo: (1) 'Ubuntu is not having a brother but being part of a bigger picture of a community, part of a nation. Having ubuntu, participating in ubuntu rather is part of a plural and not a singular, that one is part of a plural, that one has a biological family but also has something bigger than that. Ubuntu is knowing that when walking down the street and you see a young boy in distress or a couple of boys fighting, you go there and you stop them and you say 'what's wrong' you know, 'what's happening' because that boy is your younger brother, you know not your biological younger brother but your younger brother because you happen to be in something that is bigger than your family. You happen to be in family which is a community, which is a nation that is ubuntu'

(2) Ubuntu started with the beginning of time when the African people were put on this continent and they had to work together in order to survive. Plants, the vegetables and do this and that and that, do everything as a community that is where it started.

In modern days, a collective mind-set within the team is paramount for competitiveness. Competitiveness means effectiveness in comparison to other teams. The competitiveness amongst teams can be related to survival, because the teams compete to survive. Therefore, in order to be competitive and survive, teams need to have a good blend of individuals who bring in different kinds of knowledge, skills and abilities (KSAs) to ensure survival. Team members start to depend on each other, because being part 
of the collective means working together. Some participants suggested this in various statements:

Jack: '...different members of the team must bring something different in the team and prefer to have a diverse team in terms of background and skills; collective decision making is especially quicker and covers all angles of the problem'.

ATM: 'We synergise our efforts, we try to help each other, we use our strength, our outputs. For example, when a guy is good in calculations, somebody is good in making sales then we are synergising what we know, $\mathrm{mmm}$ '.

Each team member brings something different into the team constitutes teamwork. Teamwork consists of transparency, in other words openness, communication, honesty, and trustworthiness with regard to each team member. In this manner, the team members will also feel that they are part of a family, an 'extended family', as described earlier.

Once individuals feel that they are included into the community and that they depend on each other in order to survive, it is possible to mould a spirit of solidarity. When one is included in a collective setting, the ' $\mathrm{I}$ ' is eliminated automatically and the 'we' becomes more important. The collective mind-set and interconnectedness facilitate the development of a spirit of solidarity. When this spirit of solidarity develops, individuals begin to see themselves as one, as moving and pulling towards the same central goals. Then it can be argued that a 'we' state of mind is present, which again leads to cohesion. Therefore, the degree of cohesion derived from accomplishing tasks, whether they are small or mammoth, is much higher because individuals see themselves as belonging to the collective and are dependent on each other.

In essence, collectivism leads to a spirit of solidarity, which leads to cohesion. In the following quotes, participants expressed their views about (1) the creation of a spirit of solidarity, (2) the importance of the 'we' in a team and (3) cohesion in their team:

(1) Sibo: '...is made of self, self, self, I, I, I. Take all those winners and you strip them of that so that they start depending on each other, they start caring for each other, they start depending on each other, you get to make them feel that they can't do anything else without the other. When you create that sort of environment then the we comes in and the we mentality and when the we mentality has come in with those people with winners then you got a very strong competitive advantage.'

(2) Vusi: '...it kind of eliminates the I, it's more about the We. It's more about the We, the collective as opposed to I, I, I.'

(3) ATM: 'We are a great team even after the working hours we go out, spend time with each other.'
Another sub-category of ubuntu, which also stems from the spirit of solidarity, is compassion, which is a human quality resulting from understanding. Through a common understanding one is able to help the other person and to care for each other. Participants expressed this in the following quotes:

Anne: 'Like you must know the other people you must understand ...the other person. You have to understand the next person.'

Themba: 'It's about helping people. Like when somebody is sick you must help them. Looking after people.'

Compassion, displayed through a deep caring and understanding of each other, allows team members to strive towards a shared vision. Participants expressed their views on how caring and understanding (compassion) helps them strive towards a shared vision:

Vusi: 'In my team they have an understanding of each other and so they have an understanding of what the work is set out for us, what should be done, and understanding their talents, their goals.'

Sibo: 'Caring for each other. If one has got a personal problem it first starts in the team before it goes anywhere else. Making sure that everyone makes target, when you are making sure that everyone makes target you are making sure that every one is going to get paid.'

The last sub-category that emerged from the data analysis is respect. When practising the value of respect, one should not have the attitude that a person should not be respected simply because he or she is not a relative. In giving and receiving respect, a two-way process is created. According to the participants, respect is very important within ubuntu and it starts with one's self:

Sibo: 'Respect is very important. Respect is the foundation of Ubuntu, if Ubuntu can be taken and dissected respect would make a huge chunk of that. That is Ubuntu it's respect, it's caring, it's love...'

Gerry: 'It's basically neighbourliness, you know. (To recall a bit) it consists of respect... (You know) that's one of the biggest things about Ubuntu; you got to respect yourself, to be able to respect other people. I can't really show you respect if I don't really respect myself. So that's why if I am rude with you then I have very little respect for myself, to be able to treat you that way... respecting each other's values.'

Dignity is related to respect and is created through one's behaviour, for example, one's interaction with others. Participants expressed the belief that respect and dignity are important values of ubuntu: 
Wiseman: 'Respect and Dignity, these are the values of Ubuntu. Wherever you go you take these values with you.'

ATM: 'Respect of elderly people, primarily respect be it your family members or not. Interacting on a daily basis, respecting yourself, the manner in which you conduct yourself... Norms the way we talk, the way we walk, the way we wear you must cover your body properly. This displays dignity; you dignify yourself with your behaviour.'

In a team setting, team member's respect for one another is also displayed in their daily interaction. Acceptance, together with respect and dignity will ensure that trust, and more importantly, mutual trust is created.

In summary, the main finding from the data analysis is that ubuntu is a collective value system and its core social values include survival, a spirit of solidarity, compassion and respect/dignity. Collectivism is the backbone of the ubuntu way of life because, without a collective mind-set, Africans would not have been able to practice the social values of ubuntu as outlined by the research. Therefore, if this value system of ubuntu is to be applied to teams in South African organisations to ensure effectiveness, team members need to, firstly, tackle tasks collectively, secondly, see themselves as a collective and thirdly, have a collective mind-set.

\section{Recommendations for future research}

To advance theory building in afro-centric leadership and to further verify the findings of the study, it is recommended that:

- other qualitative research methods such as ethnographical, biographical or phenomenological methods be used to further develop the theory generated in this study.

- quantitative research methods should be utilised in order to supplement the developed theory.

- $\quad$ further research should be done on the practicality of the concept of values-based leadership and its ability to harness productive results with the social values of ubuntu in practice.

\section{Managerial implications}

As a value system underpins one's behaviour, the value system that a leader adheres to underpins his or her leadership behaviour. Leaders with the inherent values of ubuntu have been described as people-centred, humble, ready to enter into dialogue, caring, polite, tolerant, considerate, hospitable, and as having an attitude of mutual acceptance or mutuality (Bekker, 2006). Teams, like leaders, have tasks and responsibilities they have to accomplish collectively and values-based leadership provides team members with examples of how to regulate their behaviour collectively towards one common goal, which is effectiveness. The values of a team are reflected daily in decisions, policies, practices and culture. But, it is the task of the leader to bring the team members together to achieve a common goal.

Team members need to establish the social values of ubuntu as a set of 'group' values that every team member can buy into, while at the same time acknowledging and appreciating the differences of each team member, because the values of ubuntu can have a tremendous impact on effectiveness. The impact can range from being positive, when the values of members are similar and therefore result in stability and success for the organisation, to being negative, when a value discrepancy is perceived and there is a breakdown in loyalty, commitment and productivity amongst members (Overbeek, 2001).

In a team setting, the existence of ubuntu as a shared value system implies that team members will be encouraged to strive towards the outlined values, and this could enhance their functioning. This in itself will bring the team one step closer to being effective because of the increase in the level of team members' commitment, loyalty and satisfaction, which ultimately has a positive impact.

Conversely, a value system that is not intrinsically held by all members can have a negative impact because each team member works towards different goals based on differing value systems. This can result in dissatisfaction, lack of productivity and commitment and a lack of teamwork or team spirit amongst team members.

The task of the leader is to try and create a team culture that appreciates values of ubuntu. It is at this point that a valuesbased leader becomes important because he or she can guide all team members towards a common value system.

\section{Conclusion}

The primary goal of this study was to facilitate better integration and understanding of a multi-cultural workforce and to make a positive, constructive contribution towards successful management of diversity with a focus on teams. As traditional European and American management concepts have not always catered for the needs of a highly diverse society on the brink of rapid economic and social development, as in South Africa, the approach of this study is based on homegrown values, more specifically the value system of ubuntu. The introduction, proper implementation and the daily practice of the social values of ubuntu in organisations would not only preserve these values in the modern business world, but would also lead to team effectiveness in South Africa. However, a leader who has a values-based style of leadership, and who could be aware of and appreciate the already existing value systems within the team can only achieve such role modelling. When implemented properly, ubuntu values will increase team effectiveness and, ultimately, organisational effectiveness.

\section{References}

April, K. \& Ephraim, N. 2006. 'Implementing African leadership: An empirical basis to move beyond theory'. Paper presented at the International Conference on Value- 
based Leadership, University of Stellenbosch Business School, 14 to 16 March.

Asante, M.K. 1991. Afrocentricity. Trenton, NJ: Africa World Press.

Avolio, B. \& Gardner, W. 2005. 'Authentic leadership development: Getting to the root of positive forms of leadership’, The Leadership Quarterly, 16(3): 315-338.

Babbie, E. \& Mouton, J. 2001. The practice of social research. Cape Town: Oxford.

Bekker, C.J. 2006. 'Finding the 'other' in African Christian Leadership: Ubuntu, kenosis and mutuality'. Paper presented at the International Conference on Value-based Leadership, University of Stellenbosch Business School, 14 to 16 March.

Booysen, L. 2001. 'The duality in South African leadership: Afro-centric or Eurocentric', South African Journal of Labour Relations, Spring/Summer: 36-60.

Broodryk, J. 2002. Ubuntu: Life lessons from Africa. Pretoria: National Library.

Buskens, V. \& Raub, W. 2002. 'Embedded trust: Control and learning'. In Thye, S.R. \& Lawler, E.J. (Eds.). Group cohesion, trust and solidarity. Amsterdam: Elsevier Science Ltd, p.p.167-202.

Creswell, J. W. 1998. Qualitative inquiry and research design: Choosing among five traditions. London: Sage.

Edwards, S., Makunga, M., Ngcobo, S. \& Dhlomo, M. 2004. 'Ubuntu: A cultural method of mental health promotion', International Journal of Mental Health Promotion, 6(1): 16-21.

Engelbrecht, A.S. 2002. 'The effect of organisational leadership on value congruence and effectiveness: An integrated model', South African Journal of Economic and Management Sciences, 5(3): 589-605.

Engelbrecht, A.S., Van Aswegen, A.S. \& Theron, C.C. 2005. 'The effect of ethical values on transformational leadership and ethical climate in organisations', South African Journal of Business Management, 36(2): 19-26.

Enslin, P. \& Horsthemke, K. 2004. 'Can ubuntu provide a model for citizenship education in African democracies?', Comparative Education, 40(4): 545-558.

Fairholm, G.W. 1991. Values leadership: Towards a new philosophy of leadership. New York: Greenwood.

Glaser, B.G. \& Strauss, A.L. 1967. The discovery of the grounded theory: Strategies for qualitative research. Chicago: Aldine Atherton.

Holton, J. A. 2001. 'Building trust and collaboration in a virtual team', Team Performance Management: An International Journal, 17(1): 36-47.
Johnson, D.W. \& Johnson, F.P. 2003. Joining together: Group theory and group skills. New York: Pearson Education.

Kuczmarski, S.S. \& Kuczmarski, T.D. 1995. Values-based leadership. Paramus, NJ: Prentice-Hall.

Mangaliso, M. P. 2001. 'Building a competitive advantage from ubuntu: Management lessons from South Africa', The Academy of Management Executive, 15(3): 23-33.

Mbigi, L. 1997. Ubuntu, the African dream in management. Pretoria: Sigma.

Mbigi, L. \& Maree, J. 1995. The spirit of African transformation management. Pretoria: Sigma.

McFarlin, D.B., Coster, E.A. \& Mogale-Pretorius, C. 1999. 'South African management development in the twenty-first century', Journal of Management Development 18(1): 6378.

Nussbaum, B. 2003. 'African culture and ubuntu: Reflections of a South African in America', World Business Academy, 17(1):1-12.

Overbeek, L. 2001. 'Values, communication and leadership: An organisational perspective on their relationship'. Unpublished master's thesis, University of Stellenbosch, Stellenbosch.

Oxford Dictionary. 1988. Advanced learner's dictionary of current English. London: Oxford.

Robbins, H. \& Finley, M. 2000. Why teams don't work: What went wrong and how to make it right. London: Texere.

Robbins, S. P. 1999. Organizational behavior. $6^{\text {th }}$ Edition. Upper Saddle River, NJ: Prentice-Hall.

Schlechter, A. \& Maritz, F. 2001. 'Achieved performance excellence by practising leadership effectively', Management Today, 17(3): 42-45.

Senge, P.M. 1990. The fifth discipline: The art and practice of the learning organization. New York: Doubleday Dell.

Thomas, A. \& Schonken, J.S. 1998. 'Culture-specific management and the African management movement verifying the premises', South African Journal of Business Management, 29(2): 67-77.

Thompson, L.L. 2000. Making the team: A guide for managers. New Jersey: Prentice-Hall.

Van der Colff, L. 2003. 'Leadership lessons from the African tree', Management Decision, 41(3): 257-261.

Wheelan, S.A. 1999. Creating effective teams: A guide for members and leaders. New Delhi: Sage.

Willer, D., Borch, C. \& Willer, R. 2002. 'Building a model for solidarity and cohesion using three theories'. In Thye, 
S.R. \& Lawler, E.J. (Eds.). Group cohesion, trust and solidarity. Amsterdam: Elsevier Science Ltd.

Yukl, G. 2002. Leadership in organisations. Englewood Cliffs, NJ: Prentice-Hall. 